\title{
Comparative pharmacokinetics and pharmacodynamics of a PEGylated recombinant human growth hormone and daily recombinant human growth hormone in growth hormone- deficient children
}

This article was published in the following Dove Press journal:

Drug Design, Development and Therapy

18 December 2015

Number of times this article has been viewed

\author{
Ling Hou ${ }^{1, *}$ \\ Zhi-hang Chen ${ }^{2, *}$ \\ Dong Liu ${ }^{3}$ \\ Yuan-guo Cheng ${ }^{2}$ \\ Xiao-ping Luo' \\ 'Department of Pediatrics, Tongji \\ Hospital, Tongji Medical College, \\ Huazhong University of Science and \\ Technology, Wuhan, ${ }^{2}$ Department \\ of Pharmacy, Beijing Institute of \\ Microbiology and Epidemiology, \\ Beijing, ${ }^{3}$ Department of Pharmacy, \\ Tongji Hospital, Tongji Medical \\ College, Huazhong University of \\ Science and Technology, Wuhan, \\ People's Republic of China \\ *These authors contributed equally \\ to this study
}

Correspondence: Xiao-ping Luo Department of Pediatrics, Tongji Hospital, Tongji Medical College, Huazhong University of Science and Technology, 1095 Jiefang Avenue, Wuhan 430030, Hubei Province, People's Republic of China Tel/fax +86278366 37/2

Email xpluo@tjh.tjmu.edu.cn

Yuan-guo Cheng Department of Pharmacy, Beijing Institute of Microbiology and Epidemiology, No 20, Dongda Street, Fengtai District, Beijing I0007I, People's Republic of China

Tel +86 I0 66948493

Fax +86 I0 66948547

Email chengyg@bmi.ac.cn
Objective: Recombinant human growth hormone $(\mathrm{rhGH})$ replacement therapy in children generally requires daily subcutaneous (sc) injections, which may be inconvenient for patients. Jintrolong $^{\circledR}$ is a PEGylated rhGH with the purpose of weekly sc injections. The aim of the current study was to examine the pharmacokinetics, pharmacodynamics, safety, and tolerability of multiple sc doses of Jintrolong ${ }^{\circledR}$ vs daily doses of rhGH.

Design and methods: Twelve children with growth hormone deficiency participated in this single-center, open-label, crossover Phase I trial. All subjects received daily sc injections of $\mathrm{rhGH}$ at $0.0286 \mathrm{mg} / \mathrm{kg} / \mathrm{d}$ for 7 days, followed by a 4 -week washout period and six weekly doses of Jintrolong ${ }^{\circledR}$ at $0.2 \mathrm{mg} / \mathrm{kg} / \mathrm{w}$.

Results: In comparison with rhGH, sc injection of Jintrolong ${ }^{\circledR}$ produced a noticeably higher $C_{\max }$, significantly longer half-life $\left(t_{1 / 2}\right)$, and slower plasma clearance, signifying a profile suitable for long-term treatment. The ratio of the area under the concentration vs time curve (AUC) after the seventh and first injections $\left(\mathrm{AUC}_{(0-\infty) 7 \mathrm{th}} / \mathrm{AUC}_{(0-\infty) 1 \mathrm{st}}\right)$ of rhGH was 1.02, while the $\mathrm{AUC}_{(0-\infty) 6 \mathrm{th}} /$ $\mathrm{AUC}_{(0-\infty) 1 \mathrm{st}}$ of Jintrolong ${ }^{\mathbb{R}}$ was 1.03 , indicating no accumulation of circulating growth hormone. There was no significant difference in the change in insulin-like growth factor-1 expression produced by 7 days of sc rhGH and weekly Jintrolong ${ }^{\circledR}$ injections. There were no severe adverse events during the trial.

Conclusion: The elimination rate of Jintrolong ${ }^{\circledR}$ was slower than that of sc rhGH. No progressive serum accumulation of Jintrolong ${ }^{\circledR}$ was found. The changes in insulin-like growth factor-1 expression produced by rhGH and Jintrolong ${ }^{\circledR}$ were comparable, indicating similar pharmacodynamics. Our results demonstrate that Jintrolong ${ }^{\circledR}$ is suitable for long-term growth hormone treatment in children with growth hormone deficiency.

Keywords: long-acting growth hormone, phase I, multiple-dose

\section{Introduction}

Recombinant human growth hormone ( $\mathrm{rhGH}$ ) is primarily used to treat children with growth failure due to endogenous growth hormone deficiency (GHD). The most widely used growth hormone $(\mathrm{GH})$ replacement therapy regimen involves daily subcutaneous (sc) injections. Although the insulin-like growth factor-1 (IGF-1) level produced by daily $\mathrm{GH}$ injections was different from that produced by eight boluses of GH injection (which resembled endogenous GH secretion), ${ }^{1}$ this method produces linear growth, 
and its therapeutic potential has been well established. ${ }^{2-4}$ Furthermore, a large amount of data has demonstrated that the therapeutic consequences of rhGH therapy are not influenced by differences in injection frequency. ${ }^{5,6}$ Daily injections are burdensome for some patients and their families, resulting in very low compliance in such cases. ${ }^{7}$ Approximately $23 \%-50 \%$ of pediatric patients failed to adhere to all aspects of a GH treatment regimen, or missed two to three injections per week..$^{7-9}$

Jintrolong $^{\circledR}$ is a PEGylated long-acting rhGH, in which a $40 \mathrm{kDa}$ hydrophilic polyethylene glycol (PEG) residue is attached to rhGH. PEGylation prolongs the serum half-life of $\mathrm{GH}$ and reduces its immunogenicity. ${ }^{10}$ PEGylation of proteins does not seem to represent a safety risk to humans. ${ }^{27}$ Jintrolong $^{\circledR}$ has been developed to improve treatment convenience for patients requiring $\mathrm{GH}$ administration.

In an earlier study, we analyzed the pharmacokinetic (PK) properties of single administration of Jintrolong ${ }^{\circledR}$ at three different doses $(0.1,0.2$, and $0.4 \mathrm{mg} / \mathrm{kg} / \mathrm{w})$ in 30 healthy males (ten subjects in each group). Afterwards, the group that received $0.4 \mathrm{mg} / \mathrm{kg} / \mathrm{w}$ Jintrolong ${ }^{\circledR}$ entered a 4 -week washout period and was treated with daily injections of $\mathrm{rhGH}$ at $0.067 \mathrm{mg} / \mathrm{kg} / \mathrm{d}$ for 7 days. The results indicated that Jintrolong ${ }^{\circledR}$ had later $T_{\max }$, longer $t_{1 / 2}$, and slower plasma clearance compared with rhGH (shown in Table S1). All the subjects tolerated the three different doses well. As the medium dose of Jintrolong ${ }^{\circledR}$ used in earlier study $(0.2 \mathrm{mg} / \mathrm{kg} / \mathrm{w}=0.03 \mathrm{mg} /$ $\mathrm{kg} / \mathrm{d}$ ) was the closest to the prescribed doses of daily rhGH $\left(\right.$ Jintropin $^{\circledR}$ ) at $0.03-0.05 \mathrm{mg} / \mathrm{kg} / \mathrm{d}, 0.2 \mathrm{mg} / \mathrm{kg} / \mathrm{w}$ was chosen in the present study. We report here the first data on Jintrolong ${ }^{\circledR}$ administration to children with GHD.

\section{Subjects and methods Subjects}

The subjects were 12 boys (age $>3$ and $<16$ years) with a diagnosis of GHD as determined by the following inclusion criteria: height $<-2$ standard deviation score for chronological age, growth velocity $\leq 4.0 \mathrm{~cm} /$ year, serum $\mathrm{GH}$ peak $<7.0 \mathrm{ng} / \mathrm{mL}$ in two different $\mathrm{GH}$ stimulation tests, and bone age $\leq 10$ years and at least 2 years below the patient's chronological age (bone age was determined by the Tanner-Whitehouse 3 method $^{11}$ ). A magnetic resonance imaging scan of the pituitary gland was conducted to exclude pituitary tumors. The subjects discontinued their treatment $>4$ weeks before receiving the trial product, or never received rhGH treatment. The protocol was approved by the Chinese State Food and Drug Administration (No 2005L02779) and conducted in accordance with the
ICH guidelines for Good Clinical Practice and the Declaration of Helsinki. All of the subjects of the study signed informed consent forms.

\section{Study design}

The trial was designed as a single-center, multiple-dose study. Twelve subjects first received sc daily injections of rhGH (GeneScience Pharmaceuticals, Changchun, People's Republic of China) at $0.0286 \mathrm{mg} / \mathrm{kg}$ for 7 days, which were followed by a 28-day washout period and 6 weeks of weekly sc injection of Jintrolong ${ }^{\circledR}$ (GeneScience Pharmaceuticals) at $0.2 \mathrm{mg} / \mathrm{kg}$. The $\mathrm{PK}$ and pharmacodynamic (PD) profiles of $\mathrm{rhGH}$ and Jintrolong ${ }^{\circledR}$ were evaluated. Safety was evaluated from reported adverse events. The trial was performed at Tongji Hospital (Huazhong University of Science and Technology) and approved by the Ethics Committee.

\section{PK/PD assays}

The serum samples used to assess the PK profile of rhGH were collected 30 minutes before dosing and up to 24 hours $(1,2,3,4,6,8,10,12,16,20$, and 24 hours) after the first and seventh daily injections, as well as 4 hours after the second to sixth daily injections. The serum samples used to assess the PK profile of Jintrolong ${ }^{\circledR}$ were collected 30 minutes before dosing and up to 168 hours $(2,4,8,12,18,24,36$, $48,72,96,120,144$, and 168 hours) after the first and sixth weekly treatments, as well as 48 hours after the second to fifth weekly treatments.

Serum rhGH levels were measured with a human GH enzyme-linked immunosorbent assay (ELISA) kit $\left(\right.$ RayBio $\left.^{\circledR}\right)$ using a capture antibody specific for human $\mathrm{GH}$, a biotinylated antihuman GH antibody as the detection antibody, and a streptavidin-horseradish peroxidase conjugate as the enzyme label. Serum PEG-rhGH levels were determined with a GH ELISA kit (RayBio ${ }^{\circledR}$ ) using a capture antibody specific for human GH and a biotinylated anti-PEG antibody as the detection antibody. PK parameters were calculated based on concentration-time data. The PK parameters calculated for $\mathrm{GH}$ included the maximal serum concentration $\left(C_{\max }\right)$, time after administration of a drug when the maximum plasma concentration is reached $\left(T_{\max }\right)$, half-life $\left(t_{1 / 2}\right)$, plasma clearance (CL), area under the concentration vs time curve (AUC), mean residence time (MRT), and steady-state volume of distribution $\left(V_{\mathrm{ss}}\right)$.

Analyses of serum levels of IGF-1 and insulin-like growth factor binding protein-3 (IGFBP-3) were carried out using commercially available chemiluminescence immunoassays 
performed on an Immulite 1000 analyzer (Siemens, Munich, Germany).

\section{Safety}

The safety of Jintrolong ${ }^{\circledR}$ was assessed based on adverse events, clinical laboratory assessments, physical examinations, vital signs, electrocardiograms, and injection-site tolerability.

\section{Statistical analyses}

PK parameters were calculated based on concentration-time data with Phoenix WinNonlin software (Certara, Princeton, NJ, USA). Paired sample $t$-test was used to evaluate differences in PK parameters between the first and sixth injections of Jintrolong ${ }^{\circledR}$ and the first and seventh injections of rhGH. Differences in the change in AUC $\left(\mathrm{AUC}_{\text {change }}\right)$ from baseline for IGF-1 and IGFBP-3 after 7 days of rhGH injection and weekly Jintrolong ${ }^{\circledR}$ injections were evaluated with ANOVA.

\section{Results}

\section{Baseline characteristics}

A total of 12 subjects with GHD were enrolled (mean age was $15.13 \pm 3.77$ years; mean weight was $32.42 \pm 7.11 \mathrm{~kg}$; and mean height was $132.63 \pm 11.24 \mathrm{~cm})$. Anti-GH antibodies were negative in all subjects.

\section{PK profile of $\mathrm{GH}$}

In each case, the serum $\mathrm{GH}$ concentration before dosing was $<0.5 \mathrm{ng} / \mathrm{mL}$. After dosing with $\mathrm{rhGH}$ at $0.0286 \mathrm{mg} / \mathrm{kg}$, the serum GH concentration increased rapidly to a peak value at 3-4 hours and declined within 24 hours (Figure 1A). After administration of Jintrolong ${ }^{\circledR}$, the serum GH concentration rose rapidly from 2 to 4 hours, showed an extended peak from 24 to 72 hours, and then dropped steadily (Figure 1A and $1 \mathrm{~B})$.

The PK parameters of Jintrolong ${ }^{\circledR}$ and rhGH were comparable between the first and the last injection, and no significant differences were observed. The accumulation ratio between $\mathrm{AUC}_{(0-\infty)}$ after the seventh dosing and $\mathrm{AUC}_{(0-\infty)}$ after the first dosing $\left(\mathrm{AUC}_{(0-\infty) 7 \mathrm{th}} / \mathrm{AUC}_{(0-\infty) 1 \mathrm{st}}\right)$ was 1.02, and the $\mathrm{AUC}_{(0-\infty) 6 \mathrm{th}} / \mathrm{AUC}_{(0-\infty) 1 \mathrm{st}}$ for Jintrolong ${ }^{\circledR}$ was 1.03 , indicating no significant accumulation of circulating GH after weekly Jintrolong $^{\circledR}$ and daily rhGH injections. Following injection of Jintrolong $^{\circledR}$, higher $C_{\max }$, longer $t_{1 / 2}$ and $\mathrm{T}_{\max }$ in comparison with rhGH indicated the prolonged presence of $\mathrm{GH}$ in the circulation (data are shown in Table 1).

\section{PD changes}

The IGF-1 response after once-daily injections of rhGH and once-weekly injections of Jintrolong ${ }^{\circledR}$ was similar (Figure 2). After dosing with rhGH, the serum IGF-1 level rose gradually and reached a steady-state concentration $(157.4 \pm 65.5 \mathrm{ng} / \mathrm{mL})$ after the third dose. The accumulated increase in the IGF-1 AUC by the seventh dose of rhGH was 16,834.6 $16,732.1 \mathrm{ng} \cdot \mathrm{h} /$ $\mathrm{mL}$ (Table 2). After the first dose of Jintrolong ${ }^{\circledR}$, the serum IGF-1 level climbed steadily and reached a peak concentration at $230.4 \pm 65.1 \mathrm{ng} / \mathrm{mL}$ after 2 days, and this elevation lasted for 7 days. The serum concentration of IGF-1 $(114.2 \pm 43.9 \mathrm{ng} / \mathrm{mL})$ remained greater than the baseline concentration 7 days after the first injection, suggesting that the biological effect of Jintrolong ${ }^{\circledR}$ was maintained for at least 7 days in children with GHD. The increment in the IGF-1 AUC from baseline after the first dose of Jintrolong ${ }^{\circledR}$ was $21,973.9 \pm 5,886.9 \mathrm{ng} \cdot \mathrm{h} / \mathrm{mL}$, while the increment after
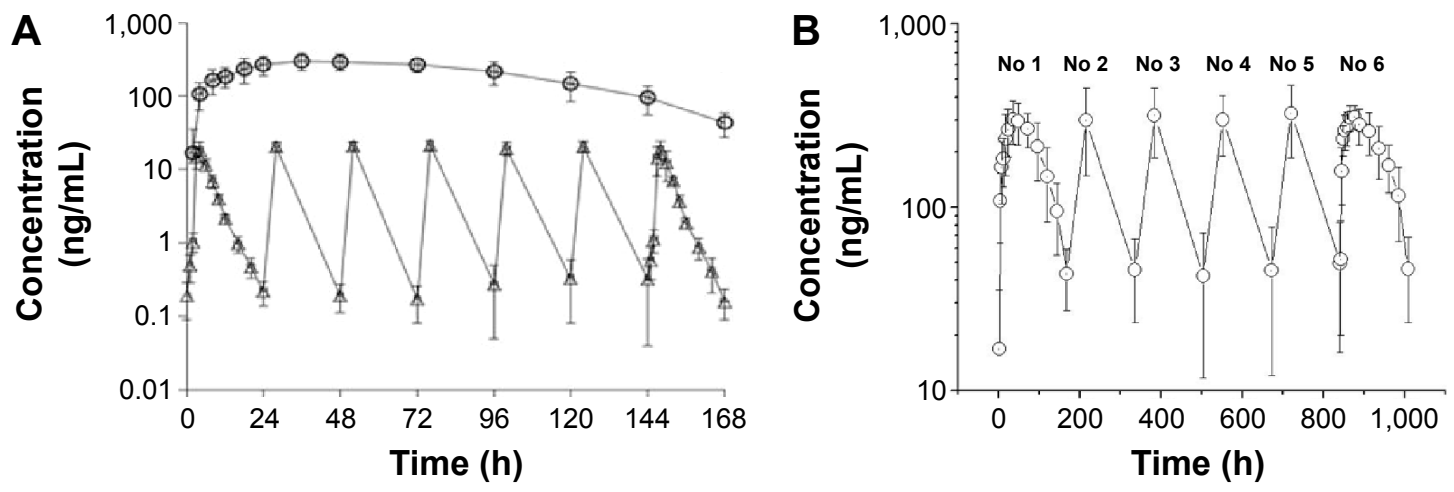

$\triangle \mathrm{rhGH} 0.0286 \mathrm{mg} / \mathrm{kg} / \mathrm{d}-\ominus$ Jintrolong $^{\circledR} 0.2 \mathrm{mg} / \mathrm{kg} / \mathrm{w}$

Figure I Serum GH concentration after administration of rhGH (jintropin $\mathrm{AQ}^{\circledR}$ ) and jintrolong ${ }^{\circledR}$.

Notes: Serum GH concentration during the course of seven doses of Jintropin $A^{\circledR}{ }^{\circledR}$ administered once per day and the first dose of Jintrolong ${ }^{\circledR}$ (PEG-GH) in children with GHD (A). Serum GH concentration during the course of six doses of Jintrolong ${ }^{\circledR}$ administered weekly for 6 weeks in children with GHD (B).

Abbreviations: GH, growth hormone; PEG-GH, PEGylated growth hormone; GHD, growth hormone deficiency; rhGH, recombinant human growth hormone; h, hours; No, number. 
Table I Pharmacokinetic parameters for rhGH and Jintrolong ${ }^{\circledR}$

\begin{tabular}{|c|c|c|c|c|c|c|}
\hline & \multicolumn{3}{|c|}{ rhGH at $0.0286 \mathrm{mg} / \mathrm{kg} / \mathrm{d}$} & \multicolumn{3}{|c|}{ Jintrolong ${ }^{\circledR}$ at $0.2 \mathrm{mg} / \mathrm{kg} / \mathrm{w}$} \\
\hline & First dose & Seventh dose & $P$-value & First dose & Sixth dose & $P$-value \\
\hline $\mathrm{N}$ & 12 & 12 & & 12 & 12 & \\
\hline$C_{\max }(\mathrm{ng} / \mathrm{mL})$ & $20.4 \pm 4.1$ & $22.4 \pm 3.8$ & 0.2283 & $327 \pm 70$ & $340 \pm 44$ & 0.5915 \\
\hline $\mathrm{AUC}_{0-168 \mathrm{~h}}(\mathrm{ng} \cdot \mathrm{h} / \mathrm{mL})$ & $103 \pm 21$ & $104 \pm 19$ & 0.9428 & $34,837 \pm 8,235$ & $37,229 \pm 7,911$ & 0.5954 \\
\hline$T_{\max }$ (hours) & $3.8 \pm 0.5$ & $3.8 \pm 0.8$ & 0.7648 & $43.0 \pm 14.9$ & $38.0 \pm 14.3$ & 0.3594 \\
\hline$t_{1 / 2}$ (hours) & $2.3 \pm 0.4$ & $2.3 \pm 0.8$ & 0.9400 & $33.0 \pm 5.7$ & $34.0 \pm 8.1$ & 0.7933 \\
\hline
\end{tabular}

Note: The results are expressed as the mean \pm SD.

Abbreviations: $\mathrm{rhGH}$, recombinant human growth hormone; $\mathrm{AUC}$, area under the concentration vs time curve; $\mathrm{N}$, number; $C_{\max }$, maximal serum concentration; $T_{\max }$, time of maximum concentration; $t_{1 / 2}$, half-life.

the sixth dose of Jintrolong ${ }^{\circledR}$ was $18,641.7 \pm 4,783.0 \mathrm{ng} \cdot \mathrm{h} / \mathrm{mL}$ (Table 2). There was no significant difference in the change in IGF-1 AUC after 7 days of daily rhGH injections or after the first and sixth weekly administrations of Jintrolong ${ }^{\circledR}(P=0.059$ and $P=0.456$, respectively). These results indicated that the PD profiles of weekly Jintrolong ${ }^{\circledR}$ administration and daily rhGH were comparable.

Serum IGFBP-3 concentrations after administration of rhGH and Jintrolong ${ }^{\circledR}$ are shown in Figure 3. After dosing with rhGH, the serum IGFBP-3 level increased gradually and reached a steady state after the fourth dose. The increase in the IGFBP-3 AUC by the seventh dose of rhGH was $190,879 \pm 66,043 \mathrm{ng} \cdot \mathrm{h} / \mathrm{mL}$ (Table 3). After the first dose of Jintrolong ${ }^{\circledR}$, the serum IGFBP-3 level rose steadily, reached a peak $(3,948 \pm 788 \mathrm{ng} / \mathrm{mL})$ after 5 days, and then gradually declined. Consistent with the changes in IGF-1, the concentration of IGFBP-3 remained greater than the baseline concentration 7 days after the first injection, indicating that the biological effect of Jintrolong ${ }^{\circledR}$ was maintained for at least 7 days in children with GHD. The increase in the IGFBP-3 AUC after

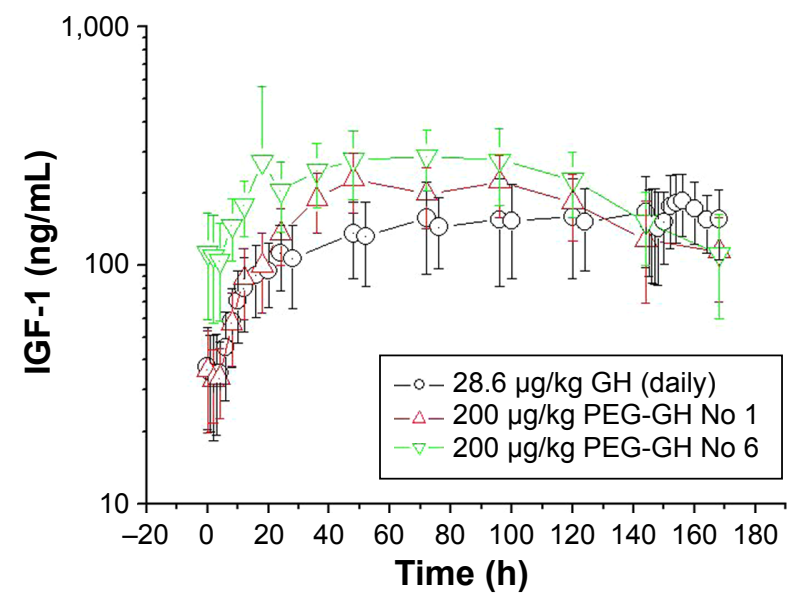

Figure 2 Serum IGF-I concentrations during the course of seven doses of Jintropin $\mathrm{AQ}^{\circledR}$ administered once per day and the first and sixth doses of jintrolong ${ }^{\circledR}$ (PEG$\mathrm{GH})$ administered weekly in children with GHD $(n=\mid 2)$.

Abbreviations: IGF-I, insulin-like growth factor-I; PEG-GH, PEGylated growth hormone; GHD, growth hormone deficiency; GH, growth hormone; No, number; h, hours. the first dose of Jintrolong ${ }^{\circledR}$ was $239,726 \pm 86,217 \mathrm{ng} \cdot \mathrm{h} / \mathrm{mL}$ (Table 3). The IGFBP-3 AUC after 7 days of rhGH daily injections and after the first week injection of Jintrolong ${ }^{\circledR}$ was not significantly different $(P=0.133)$. However, the increase in IGFBP-3 after the sixth weekly administration of Jintrolong $^{\circledR}$ was significantly lower than that after the first weekly administration $(P=0.004)$, which might be attributed to the significantly higher IGFBP-3 concentration before the sixth dose of Jintrolong ${ }^{\circledR}$ in comparison with that before the first administration. These results likely indicated that IGFBP-3 reached a saturated state after multiple doses of Jintrolong ${ }^{\circledR}$.

\section{Safety}

Laboratory tests were performed before compound administration and after six doses of Jintrolong ${ }^{\circledR}$. To protect the well-being of the research participants, no laboratory tests were performed during or after rhGH administration (first week of the study) or during the washout period (second to fifth week of the study), reducing the frequency of blood sample collection.

In both treatment regimens, no serious adverse events occurred. No injection-site reactions, such as pain, redness, nodules, and lipoatrophy, were reported in the present study. Furthermore, headache, joint pain, and swelling were also not reported. Adverse events classified as possibly drugrelated had occurred in four patients by the end of Jintrolong ${ }^{\circledR}$ treatment. The serum total thyroxine (TT4) levels of the patients with adverse events that were possibly drug-related were lower than the reference range, and these patients were diagnosed with an isolated decrease in serum $\mathrm{T} 4$. However, the difference in the pre- and posttreatment $\mathrm{T} 4$ levels in these patients was not significant $(P>0.05)$. After Jintrolong ${ }^{\circledR}$ treatment, serum alkaline phosphatase levels were significantly increased from baseline, while total cholesterol and low-density lipoprotein (LDL) levels were significantly decreased from baseline $(P<0.05)$. Serum calcium, phosphorus, fasting glucose, $\mathrm{HbA}_{1 \mathrm{l}}$, renal function 
Table 2 The accumulated change in $A \cup C\left(A \cup C_{\text {change }}\right.$ ) from baseline for serum IGF-I during the course of seven doses of Jintropin $A Q{ }^{\circledR}$ and the first and sixth doses of Jintrolong ${ }^{\circledR}$ in children with GHD $(n=12)$

\begin{tabular}{|c|c|c|c|c|}
\hline Group & Treatment & AUC $_{\text {total }}$ & AUC $_{\text {baseline }}$ & AUC $_{\text {change }}$ \\
\hline $\mathrm{rhGH}$ & $0.0286 \mathrm{mg} / \mathrm{kg} / \mathrm{d} \times 7$ & $23,133.2 \pm 8,3 \mid 6.5$ & $6,298.6 \pm 2,86 \mid .8$ & $16,834.6 \pm 6,732.1$ \\
\hline Jintrolong ${ }^{\circledR}$ first & $0.2 \mathrm{mg} / \mathrm{kg} / \mathrm{w}$ & $28,097.5 \pm 6,858.0$ & $6,123.6 \pm 2,797.8$ & $21,973.9 \pm 5,886.9$ \\
\hline Jintrolong ${ }^{\circledR}$ sixth & $0.2 \mathrm{mg} / \mathrm{kg} / \mathrm{w}$ & $37,541.7 \pm 9,928.2$ & $18,900.0 \pm 9,0 \mid 5.6$ & $|8,64| .7 \pm 4,783.0$ \\
\hline
\end{tabular}

Note: The results are expressed as the mean \pm SD.

Abbreviations: AUC, area under the concentration vs time curve; IGF-I, insulin-like growth factor-I; GHD, growth hormone deficiency; rhGH, recombinant human growth hormone.

parameters, and electrocardiogram parameters remained normal throughout the course of Jintrolong ${ }^{\circledR}$ treatment.

\section{Discussion}

It has been reported that children, adolescents, and adults receiving GH had low compliance after 2 years of treatment, and that difficulties with injections played a major role in this low compliance. ${ }^{12}$ Therefore, attempts have been made to reduce the frequency of $\mathrm{GH}$ injections for patients requiring GH therapy. ${ }^{13}$ Jintrolong ${ }^{\circledR}$ was synthesized by the addition of a $40 \mathrm{kDa}$ PEG residue to the amino group of GH. Nearly 20 years of clinical application has fully demonstrated the safety of the PEGylation technique. ${ }^{14}$

rhGH, a short-acting GH shown to be efficacious and safe in children with GHD, was compared with Jintrolong ${ }^{\circledR}$ in this study as a control agent. After sc injection of Jintrolong ${ }^{\circledR}, t_{1 / 2}$ was significantly longer and $C_{\max }$ was noticeably higher in comparison with rhGH, signifying a suitable profile for longterm treatment. In addition, $t_{1 / 2}$ was significantly longer after the first dose of Jintrolong ${ }^{\circledR}$ (33.0 \pm 5.7 hours) in comparison with that of LB03002 (12 hours), a sustained-release GH

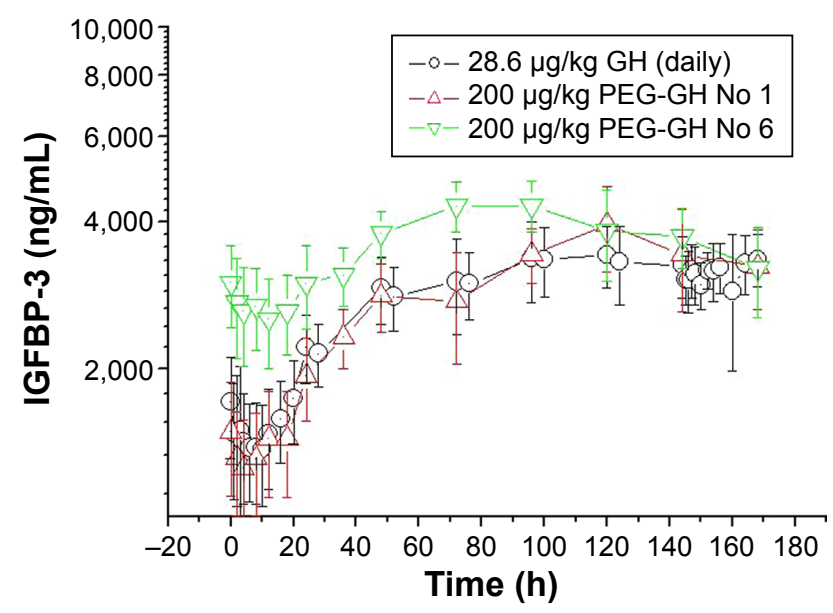

Figure 3 Serum IGFBP-3 concentrations during the course of seven doses of Jintropin $\mathrm{AQ}^{\circledR}$ administered once per day and the first and sixth doses of Jintrolong ${ }^{\circledR}$ (PEG-GH) administered weekly in children with GHD $(n=12)$.

Abbreviations: IGFBP-3, insulin-like growth factor binding protein-3; PEG-GH, PEGylated growth hormone; GHD, growth hormone deficiency; $\mathrm{GH}$, growth hormone; No, number; h, hours. suspension of microparticles consisting of GH incorporated into sodium hyaluronate, ${ }^{15}$ suggesting a longer duration of treatment. The concentration-time curve profiles measured after the first and sixth doses of Jintrolong ${ }^{\circledR}$ were comparable. The ratio of the AUC of the sixth and first injections $\left(\mathrm{AUC}_{(0-\infty) 6 \mathrm{th}} / \mathrm{AUC}_{(0-\infty) 1 \mathrm{st}}\right)$ of Jintrolong ${ }^{\mathbb{B}}$ was 1.03 , indicating no accumulation of circulating $\mathrm{GH}$ after weekly administration of Jintrolong ${ }^{\circledR}$. Serum GH remained detectable in samples from all patients 168 hours after dosing (Figure 1B). The PK data suggested that Jintrolong ${ }^{\circledR}$ possesses a suitable profile for once-weekly treatment.

In a study performed by Peter et al, the subjects used to study the PK and PD profiles of LB03002, a sustained-release rhGH, included more boys than girls. ${ }^{15}$ In another study, the prevalence of GHD in males was three times higher than that in females. ${ }^{16}$ The number of subjects enrolled in this study was relatively small; as a consequence, 12 of the enrolled subjects were male, despite the fact that sex was not limited in the research design of the study.

Bidlingmaier et al studied the PK and PD profile of LB03002. ${ }^{17}$ In their study, GH levels were determined using an immunofunctional assay, in which an anti-human growth hormone (-hGH) monoclonal antibody recognizing binding site 2 of hGH was used to capture hGH from the serum sample. Thus, only those GH molecules that retained two intact binding sites for the $\mathrm{GH}$ receptor and were expected to be biologically active were recognized. In another PK/PD study of PHA-794428, the PEGylation has been used to reduce the affinity of PHA-794428 for the human GH receptor by $\sim 20$-fold, resulting in a ten- to 20 -fold increase in area under the curve compared with $\mathrm{rhGH} .{ }^{18}$ These findings possibly explained the much higher level of serum GH detected after administration of Jintrolong ${ }^{\circledR}$. However, the ELISA kit (DSL10-11100 produced by Diagnostic Systems Laboratories, Inc., Webster, NY, USA) that specifically recognized biologically active hGH went out of production before we started this study. In upcoming research, a test method able to recognize biologically active GH should be explored further. 
Table 3 The accumulated change in AUC $\left(A \cup C_{\text {change }}\right)$ from baseline for serum IGFBP-3 during the course of seven doses of Jintropin $\mathrm{AQ}^{\circledR}$ and the first and sixth doses of Jintrolong ${ }^{\circledR}$ in children with GHD $(n=12)$

\begin{tabular}{lllll}
\hline Group & Treatment & AUC $_{\text {total }}$ & AUC $_{\text {baseline }}$ & AUC $_{\text {change }}$ \\
\hline Jintropin AQ & $0.0286 \mathrm{mg} / \mathrm{kg} / \mathrm{d} \times 7$ & $473,209 \pm 64,179$ & $287,994 \pm 67,577$ & $190,879 \pm 66,043$ \\
Jintrolong first & $0.2 \mathrm{mg} / \mathrm{kg} / \mathrm{w}$ & $490,046 \pm 64,813$ & $250,320 \pm 65,448$ & $239,726 \pm 86,217$ \\
Jintrolong sixth & $0.2 \mathrm{mg} / \mathrm{kg} / \mathrm{w}$ & $615,947 \pm 66,064$ & $505,120 \pm 96,408$ & $110,827 \pm 53,186$ \\
\hline
\end{tabular}

Note: The results are expressed as the mean \pm SD.

Abbreviations: AUC, area under the concentration vs time curve; IGFBP-3, insulin-like growth factor binding protein-3; GHD, growth hormone deficiency.

GH acts directly and indirectly on peripheral tissue to promote linear growth, and this process is mediated by IGF-1. ${ }^{19}$ IGF-1 and IGFBP-3 serve as PD and safety indicators of GH. IGF-1 and IGFBP-3 increased slowly following the peak concentration of rhGH in a manner independent of the pulsatile nature of GH secretion. ${ }^{20} \mathrm{~A}$ study performed by Jorgensen et al showed that continuous infusion of $\mathrm{GH}$ and small, but frequent, intravenous boluses (resembling endogenous GH secretion) was equally effective in generating an increase in IGF-1 in GHD human subjects, whereas administration of the same amount of GH as two large boluses every day resulted in a significantly smaller rise in serum IGF-1. ${ }^{1}$ This study indicates that continuous infusion of GH better resembles the biological effects of GH pulses in comparison with intermittent administration of short-acting GH (two injections per day). Another study compared the metabolic effects of GH after continuous and intermittent sc delivery ${ }^{6}$ and found that serum levels of IGF-1 tended to increase in the patients switched to continuous infusion in comparison with that of the patients who received daily injections, but the difference was not significant $(P=0.34)$. Our PD study produced similar results, and the difference in the accumulated increase in the IGF-1 AUC for 7 days of rhGH injection and the first and the sixth weekly administration of Jintrolong ${ }^{\circledR}$ was not significant $(P=0.059$ and $P=0.456$, respectively), indicating that weekly Jintrolong ${ }^{\circledR}$ administration and daily rhGH administration had comparable PD profiles. Nevertheless, after the first weekly dose of Jintrolong ${ }^{\circledR}$, the increase in the IGF-1 AUC tended to be higher than the accumulated increase after 7 days of rhGH injection $(P=0.059)$. We concluded that the long-acting $\mathrm{GH}$ formulation Jintrolong ${ }^{\circledR}$ produced effects that better resembled the biological effects of $\mathrm{GH}$ pulse release in comparison with daily GH injections, for three reasons. First, Jintrolong ${ }^{\circledR}$ produced a stable GH concentration within the physiological range, resembling continuous intravenous infusion. Second, continuous infusion of GH produced effects that resembled the biological consequences of pulsatile GH secretion by generating a higher level of IGF-1 in comparison with that produced by a regimen of two injections per day. ${ }^{1}$ Third, this study showed that the increase in IGF-1 content from baseline tended to be higher than the corresponding increase produced after rhGH injection.

Injection site pain was the most frequently reported treatment-related adverse event after administration of longacting GH encapsulated in microspheres. ${ }^{13,21}$ In a pilot study of the once-weekly PEGylated GH formulation PHA-794428 in GH-deficient adults, PEG-GH was associated with an increased risk of developing lipoatrophy at the injection site. ${ }^{22}$ However, there were no signs of injection-site reactions or lipoatrophy in any subject during the current trial.

Laboratory studies documented a significant increase in serum alkaline phosphatase after Jintrolong ${ }^{\circledR}$ treatment. Serum alkaline phosphatase serves as a useful marker for bone formation and a potential predictor of the effectiveness of GH therapy. ${ }^{23}$ The elevated serum alkaline phosphatase level observed in this study reflected increased osteoblast activity following accelerated bone growth. A previous study showed that total cholesterol and LDL levels in children with GHD were higher than those of control patients. ${ }^{24}$ In the current trial, Jintrolong ${ }^{\circledR}$ treatment improved lipid profiles in children with GHD by reducing total cholesterol and LDL levels, which was consistent with other reports. ${ }^{24,25}$ In this study, the serum TT4 level was below the normal range in four patients. Decreased serum TT4 may be due to increased conversion of T4 to T3 as a consequence of compensatory augmentation of $5^{\prime}$-deiodinase in order to meet the demands of rapid growth. ${ }^{26}$ Short-term Jintrolong ${ }^{\circledR}$ treatment did not exert an unfavorable effect on glucose metabolism in this trial.

Administration of PEGylated proteins to animals has been associated with cellular vacuolation in macrophages in some cases. ${ }^{27,28}$ Following long-term, high-dose PEGylated protein exposure, vacuolated macrophages appear in some organs, including the liver, kidney, urinary bladder, and brain choroid plexus (CP). Vacuolation of macrophages is generally considered a normal physiological response that removes foreign bodies via scavenger phagocytes, with no obvious effects on cell function or viability. ${ }^{29}$ However, distortion of vacuoles might compress nuclei and thereby potentially 
influence cellular functions, and in the case of the $\mathrm{CP}$, this change could result in decreased production of cerebrospinal fluid. Unfortunately, whereas liver and renal function can be monitored, there are no clinical markers of $\mathrm{CP}$ function. In addition, while some PEGylated proteins have been used for a long term in pediatric patients, it is currently uncertain whether this patient group is more sensitive than adults to the effects of PEGylated proteins on the CP. ${ }^{30}$

In our previous long-term study of Jintrolong ${ }^{\circledR}$ toxicity in cynomolgus monkeys and juvenile rats, we performed hematoxylin and eosin staining of tissue sections of 39 organs from all animals that received Jintrolong ${ }^{\circledR}$. We did not observe tissue or organ vacuolation in cynomolgus monkeys that received Jintrolong ${ }^{\circledR}$ for 6 months (with rhGH at a maximum dose of $6 \mathrm{mg} / \mathrm{kg} / \mathrm{w}$ ) or in juvenile rats that received Jintrolong ${ }^{\circledR}$ for 13 weeks (with rhGH at a maximum dose of $45 \mathrm{mg} / \mathrm{kg} / \mathrm{w}$ ). Monthly PEG exposure in cynomolgus monkeys was calculated to be $1.09 \mu \mathrm{mol} /$ $\mathrm{kg} /$ month.

PEG vacuolation within $\mathrm{CP}$ ependymal cells has been observed only when the following conditions were fulfilled: 1) the subjects were cynomolgus monkeys; 2) the PEG moiety size was at least $40 \mathrm{kDa} ; 3$ ) the study duration was at least 6 weeks; and 4) monthly PEG exposure was at least $0.4 \mu \mathrm{mol} / \mathrm{kg} / \mathrm{month}$ (PEGylated $\mathrm{rhGH}$ ). Our toxicity study in cynomolgus monkeys fulfilled the above-mentioned four conditions; however, we did not observe tissue vacuolation for reasons that could not be explained. It is likely that differences in PEG structure could play a role in PEG vacuolation. In Jintrolong ${ }^{\circledR}$, a $40 \mathrm{kDa}$ branched PEG is conjugated to rhGH instead of a linear PEG. The advantage of this branched PEG residue is that it may slowly release one of the two PEG lysine-linked chains by cleavage of the carbamate linkage between polymer chains and the branching unit, thus expediting its clearance from the body. The ease with which polymer chains in branched PEGs are cleaved may play an important role in their removal from the body. ${ }^{31}$ Further long-term toxicity studies in cynomolgus monkeys must be undertaken to explore this safety issue of PEGylated proteins.

In this study, we compared the PK and PD profiles of a long-acting GH formulation after multiple doses of daily rhGH in prepubertal children with GHD. The elimination rate of Jintrolong ${ }^{\circledR}$ was slower than that of rhGH injected daily. IGF-1 increased following a single administration of Jintrolong ${ }^{\circledR}$, and this increase lasted for 7 days, suggesting a profile suitable for once-weekly treatment. No accumulation of GH was observed with continued Jintrolong ${ }^{\circledR}$ administration. The changes in IGF-1 produced by daily
GH and Jintrolong ${ }^{\circledR}$ were comparable. Importantly, multiple Jintrolong ${ }^{\circledR}$ administrations appeared to be safe and were well tolerated, and no injection-site reactions were observed. Jintrolong ${ }^{\circledR}$ offers a feasible option for patients receiving daily $\mathrm{GH}$ and is a suitable candidate for long-term treatment in children with GHD.

\section{Acknowledgment}

This study was supported by 12 th five-year plan national key technology R\&D program (2012BAI09B04) and Program for Changjiang Scholars and Innovative Research Team in University (PCSIRT1131).

\section{Disclosure}

The authors report no conflicts of interest in this work.

\section{References}

1. Jorgensen JO, Moller N, Lauritzen T, Christiansen JS. Pulsatile versus continuous intravenous administration of growth hormone $(\mathrm{GH})$ in GH-deficient patients: effects on circulating insulin-like growth factor-I and metabolic indices. The Journal of Clinical Endocrinology and Metabolism. 1990;70(6):1616-1623.

2. Cutfield W, Lindberg A, Albertsson Wikland K, Chatelain P, Ranke MB, Wilton P. Final height in idiopathic growth hormone deficiency: the KIGS experience. KIGS International Board. Acta Paediatrica. 1999;88(428):72-75.

3. Ranke MB, Lindberg A, Albertsson-Wikland K, Wilton P, Price DA, Reiter EO. Increased response, but lower responsiveness, to growth hormone $(\mathrm{GH})$ in very young children (aged $0-3$ years) with idiopathic GH Deficiency: analysis of data from KIGS. The Journal of Clinical Endocrinology and Metabolism. 2005;90(4):1966-1971.

4. Leschek EW, Rose SR, Yanovski JA, et al. Effect of growth hormone treatment on adult height in peripubertal children with idiopathic short stature: a randomized, double-blind, placebo-controlled trial. The Journal of Clinical Endocrinology and Metabolism. 2004;89(7): 3140-3148.

5. Amato G, Mazziotti G, Di Somma C, et al. Recombinant growth hormone $(\mathrm{GH})$ therapy in GH-deficient adults: a long-term controlled study on daily versus thrice weekly injections. The Journal of Clinical Endocrinology and Metabolism. 2000;85(10):3720-3725.

6. Laursen T, Gravholt CH, Heickendorff L, et al. Long-term effects of continuous subcutaneous infusion versus daily subcutaneous injections of growth hormone $(\mathrm{GH})$ on the insulin-like growth factor system, insulin sensitivity, body composition, and bone and lipoprotein metabolism in GH-deficient adults. The Journal of Clinical Endocrinology and Metabolism. 2001;86(3):1222-1228.

7. Smith SL, Hindmarsh PC, Brook CG. Compliance with growth hormone treatment - are they getting it? Archives of Disease in Childhood. 1993;68(1):91-93.

8. Desrosiers P, O'Brien F, Blethen S. Patient outcomes in the GHMonitor: the effect of delivery device on compliance and growth. Pediatric Endocrinology Reviews: PER. 2005;2 Suppl 3:327-331.

9. Kapoor RR, Burke SA, Sparrow SE, et al. Monitoring of concordance in growth hormone therapy. Archives of Disease in Childhood. 2008; 93(2):147-148.

10. Clark R, Olson K, Fuh G, et al. Long-acting growth hormones produced by conjugation with polyethylene glycol. The Journal of Biological Chemistry. 1996;271(36):21969-21977.

11. Tanner JM, Healy M JR, Goldstein H, Cameron N. Assessment of Skeletal Maturity and Prediction of Adult Height (TW3 Method). 3rd ed. London: W.B. Saunders; 2001. 
12. Rosenfeld RG, Bakker B. Compliance and persistence in pediatric and adult patients receiving growth hormone therapy. Endocrine Practice: Official Journal of the American College of Endocrinology and the American Association of Clinical Endocrinologists. 2008;14(2): $143-154$.

13. Reiter EO, Attie KM, Moshang T Jr, et al. A multicenter study of the efficacy and safety of sustained release $\mathrm{GH}$ in the treatment of naive pediatric patients with $\mathrm{GH}$ deficiency. The Journal of Clinical Endocrinology and Metabolism. 2001;86(10):4700-4706.

14. Booth C, Gaspar HB. Pegademase bovine (PEG-ADA) for the treatment of infants and children with severe combined immunodeficiency (SCID). Biologics: Targets \& Therapy. 2009;3:349-358.

15. Peter F, Savoy C, Ji HJ, Juhasz M, Bidlingmaier M, Saenger P. Pharmacokinetic and pharmacodynamic profile of a new sustained-release GH formulation, LB03002, in children with GH deficiency. European Journal of Endocrinology/European Federation of Endocrine Societies. 2009;160(3):349-355.

16. Bao XL, Shi YF, Du YC, Liu R, Deng JY, Gao SM. Prevalence of growth hormone deficiency of children in Beijing. Chinese Medical Journal. 1992;105(5):401-405.

17. Bidlingmaier M, Kim J, Savoy C, et al. Comparative pharmacokinetics and pharmacodynamics of a new sustained-release growth hormone (GH), LB03002, versus daily GH in adults with GH deficiency. The Journal of Clinical Endocrinology and Metabolism. 2006;91(8): 2926-2930.

18. Webster R, Xie R, Didier E, et al. PEGylation of somatropin (recombinant human growth hormone): impact on its clearance in humans. Xenobiotica; the Fate of Foreign Compounds in Biological Systems. 2008;38(10):1340-1351.

19. Salvatori R. Growth hormone and IGF-1. Reviews in Endocrine \& Metabolic Disorders. 2004;5(1):15-23.

20. Keller A, Wu Z, Kratzsch J, et al. Pharmacokinetics and pharmacodynamics of GH: dependence on route and dosage of administration. European Journal of Endocrinology/European Federation of Endocrine Societies. 2007;156(6):647-653.

21. Silverman BL, Blethen SL, Reiter EO, Attie KM, Neuwirth RB, Ford KM. A long-acting human growth hormone (Nutropin Depot): efficacy and safety following two years of treatment in children with growth hormone deficiency. Journal of Pediatric Endocrinology \& Metabolism: JPEM. 2002;15 Suppl 2:715-722.

22. Touraine P, D'Souza GA, Kourides I, et al. Lipoatrophy in GH deficient patients treated with a long-acting pegylated GH. European Journal of Endocrinology/European Federation of Endocrine Societies. 2009;161(4):533-540.
23. Tobiume H, Kanzaki S, Hida S, et al. Serum bone alkaline phosphatase isoenzyme levels in normal children and children with growth hormone $(\mathrm{GH})$ deficiency: a potential marker for bone formation and response to GH therapy. The Journal of Clinical Endocrinology and Metabolism. 1997;82(7):2056-2061.

24. Ciresi A, Amato MC, Criscimanna A, et al. Metabolic parameters and adipokine profile during $\mathrm{GH}$ replacement therapy in children with $\mathrm{GH}$ deficiency. European Journal of Endocrinology/European Federation of Endocrine Societies. 2007;156(3):353-360.

25. Kearney T, de Gallegos CN, Proudler A, et al. Effects of short- and long-term growth hormone replacement on lipoprotein composition and on very-low-density lipoprotein and low-density lipoprotein apolipoprotein B100 kinetics in growth hormone-deficient hypopituitary subjects. Metabolism: Clinical and Experimental. 2003;52(1):50-59.

26. Rezvani I, DiGeorge AM, Dowshen SA, Bourdony CJ. Action of human growth hormone $(\mathrm{hGH})$ on extrathyroidal conversion of thyroxine (T4) to triiodothyronine (T3) in children with hypopituitarism. Pediatric Research. 1981;15(1):6-9.

27. Webster R, Elliott V, Park BK, et al. PEG and PEG conjugates toxicity: towards an understanding of the toxicity of PEG and its relevance to PEGylated biologicals. In: Veronese, FM, editor. PEGylated Protein Drugs: Basic Science and Clinical Applications (Milestones in Drug Therapy). Birkhauser: 2009:127-146.

28. Rudmann DG, Alston JT, Hanson JC, Heidel S. High molecular weight polyethylene glycol cellular distribution and PEG-associated cytoplasmic vacuolation is molecular weight dependent and does not require conjugation to proteins. Toxicologic Pathology. 2013;41(7):970-983.

29. Kronenberg S, Baumann A, de Haan L, et al. Current challenges and opportunities in nonclinical safety testing of biologics. Drug Discovery Today. 2013;18(23-24):1138-1143.

30. CHMP Safety Working Party's response to the PDCO regarding the use of PEGylated drug products in the paediatric population. Available from: http://www.ema.europa.eu/ema/index.jsp?curl=pages/regulation/ document_listing/document_listing_000087.jsp. Accessed December 22, 2014.

31. Guiotto A, Canevari M, Pozzobon M, Moro S, Orsolini P, Veronese FM. Anchimeric assistance effect on regioselective hydrolysis of branched PEGs: a mechanistic investigation. Bioorganic \& Medicinal Chemistry. 2004;12(19):5031-5037. 


\section{Supplementary material}

Table SI Pharmacokinetic parameters for rhGH and Jintrolong ${ }^{\circledR}$ in healthy adults

\begin{tabular}{|c|c|c|c|c|}
\hline & \multicolumn{3}{|c|}{ Jintrolong $^{\circledR}(\mathrm{mg} / \mathrm{kg} / \mathrm{w})$} & \multirow{2}{*}{$\frac{\mathrm{rhGH}(\mathrm{mg} / \mathrm{kg} / \mathrm{d})}{0.067}$} \\
\hline & 0.1 & 0.2 & 0.4 & \\
\hline$N$ & 10 & 10 & 10 & 10 \\
\hline Sex & Male & Male & Male & Male \\
\hline$C_{\max }(\mathrm{ng} / \mathrm{mL})$ & $105.24 \pm 45.37$ & $379.09 \pm 109.61$ & $920.69 \pm 293.21$ & $30.17 \pm 3.20$ \\
\hline$A \cup C_{0-t}(n g \cdot h / m L)$ & $4,543.91 \pm 2,332.79$ & $25,085.27 \pm 9,388.52$ & $74,062.03 \pm 28,915.02$ & $232.78 \pm 36.60$ \\
\hline$T_{\max }$ (hours) & $22.20 \pm 9.82$ & $29.40 \pm 10.75$ & $40.80 \pm 8.39$ & $3.2 \pm 1.1$ \\
\hline$t_{1 / 2}$ (hours) & $31.70 \pm 4.70$ & $32.19 \pm 4.58$ & $30.39 \pm 5.93$ & $1.95 \pm 0.44$ \\
\hline MRT (hours) & $40.86 \pm 9.18$ & $49.90 \pm 7.53$ & $60.92 \pm 7.29$ & $6.20 \pm 0.39$ \\
\hline$V_{d} / F(\mathrm{~mL} / \mathrm{kg})$ & $\mathrm{I}, 227.6 \mathrm{I} \pm 592.64$ & $439.44 \pm 237.36$ & $268.85 \pm 116.80$ & $787.59 \pm|55.7|$ \\
\hline $\mathrm{CL} / \mathrm{F}(\mathrm{mL} / \mathrm{kg} / \mathrm{h})$ & $26.97 \pm 13.86$ & $9.21 \pm 4.05$ & $6.31 \pm 2.93$ & $284.26 \pm 43.47$ \\
\hline
\end{tabular}

Note: The results are expressed as the mean \pm SD.

Abbreviations: $\mathrm{rhGH}$, recombinant human growth hormone; $\mathrm{AUC}$, area under the concentration vs time curve; $\mathrm{MRT}$, mean residence time; $\mathrm{CL}$, clearance; h, hours; $\mathrm{N}$, number; $C_{\max }$, maximal serum concentration; $T_{\max }$, time of maximum concentration; $t_{1 / 2}$, half-life; $V_{\mathrm{d}} / F$, apparent volume of distribution; $C L / F$, apparent total clearance.

\section{Publish your work in this journal}

Drug Design, Development and Therapy is an international, peerreviewed open-access journal that spans the spectrum of drug design and development through to clinical applications. Clinical outcomes, patient safety, and programs for the development and effective, safe, and sustained use of medicines are a feature of the journal, which has also been accepted for indexing on PubMed Central. The manuscript management system is completely online and includes a very quick and fair peer-review system, which is all easy to use. Visit http://www.dovepress.com/testimonials.php to read real quotes from published authors.

Submit your manuscript here: http://www.dovepress.com/drug-design-development-and-therapy-journal 